\title{
Is It Time to Rethink Our Software Development Practices?
}

\author{
S. Parthasarathy, Thiagarajar College of Engineering, India \\ iD https://orcid.org/0000-0001-7439-6878 \\ Thangavel Chandrakumar, Thiagarajar College of Engineering, India \\ (iD) https://orcid.org/0000-0002-1186-5988
}

\begin{abstract}
COVID-19 has proliferated across the nations with an increasing number of cases each day. Thus, IT companies are now forced to operate from remote places with limited IT resources. However, these companies across the globe are in continuous touch with their software development and maintenance teams to ensure that they are productive and able to deliver their services on the projects on time. The authors study the challenges faced by the IT companies at this juncture and the need for a different software development approach to complete the projects successfully even during such crisis. In this context, when the IT industries are making attempts to complete their on-going software projects and also to attend to some critical up-gradation in their previously delivered products, the challenges faced by them due to acute shortage of IT resources and transforming the working model from physical setup to remote platform needs to be studied. This calls for studying the existing software development models and practices and defining an alternate one that would suit the present IT scenario.
\end{abstract}

\section{KEYWORDS}

Model, Performance, Project Management, Software Development

\section{INTRODUCTION}

Since the beginning of 2020, the COVID-19 pandemic has emerged as a significant and very global challenge that imposes huge restrictions on the way an IT company conducts its software development and business consulting across the globe. COVID-19 has become a global pandemic straining the health systems in many countries. In the absence of a COVID-19 vaccine, social distancing and 'working from home' are considered to be the ideal solutions to control the transmission of the deadly corona virus from one person to another. The smooth functioning of all of these IT companies is very essential during a period of lockdown and social distancing. They are required to help an IT company's existing customers use their digital solutions without any interruptions.

During the COVID-19 crisis, some of these companies have proactively deployed collaboration IT platforms, cloud-enabled IT infrastructure, and robust security practices and policies to facilitate their development teams in continuing to work on their software projects. In this context, when the IT industries are making attempts to complete their on-going software projects and to attend to some critical updation to their previously delivered products, the challenges faced by them because of an acute shortage of IT resources and the transformation of the working model from a physical setup

DOI: 10.4018/JCIT.20211001.oa14

This article published as an Open Access article distributed under the terms of the Creative Commons Attribution License (http://creativecommons.org/licenses/by/4.0/) which permits unrestricted use, distribution, and production in any medium, provided the author of the original work and original publication source are properly credited. 
to a remote platform need to be studied. This calls for studying the existing software development models and practices and defining an alternate that would suit the present IT scenario.

Over the past three decades, software projects have become increasingly global. This change has been driven by the digitisation of industries involved in the manufacturing of goods and in other services sectors such as education, healthcare, banking, and insurance (Allen and Christopher, 2007). The COVID-19 pandemic is severely impacting the business processes of all of these industries. This new situation has forced every industry to adjust its limited resources to carry out its business processes, and doing so requires additional effort and time. Systems engineering (SE) and software engineering $(\mathrm{SwE})$ are therefore interdependent, tightly coupled, and complementary activities that must be carefully aligned and coordinated throughout the system development process (Gralha et al., 2018; Jbara et al. 2020). The COVID-19 pandemic has come as a wake-up call for project managers to rethink the development of a software product by a team involving developers, business analysts, and solution architects. Since the beginning of 2020, because of this pandemic, globally, the on-time completion of software projects has been considered to be a dream come true for many project managers.

The existing software development models (Chen and Huang, 2009)(Hatton and Rutkowski, 2009) and practices do not seem to help these managers carry out their software development processes without any hiccups and deliver the intermediate or the final product on time. The present unrest caused by COVID-19 in the IT industry invites software engineering (SE) researchers and practitioners to consider designing an interactive software development model (ISDM) and practices that will improve their resilience to such distress. Our research objective is to propose a high-level view of such a model designed based on a survey with project managers working in IT companies in remote mode during the present crisis.

\section{SOFTWARE DEVELOPMENT PRACTICES}

The existing software development models (Chen and Huang, 2009) (Hatton and Rutkowski, 2009) and practices including the most widely used agile methods require that the software development team members be able to work in a controlled setup with sufficient IT resources and manpower. All of these models did not yet foresee the 'hard side' of software development and maintenance that may be experienced during a global crisis such as the COVID-19 one, which has forced the IT industry to operate in the remote mode because of the worldwide lockdown. Such crisis conditions are characterised by hardly formalisable problems, rapidly changing requirements, and other limitations, such as extremely limited IT resources and lack of skilled manpower.

In a previous study, Zykov (2016) observed that project managers during a crisis and the resulting period of uncertainty may use agile methods for software development, but doing so requires special techniques and a high level of discipline along with developers with a reasonable number of years of experience. Without all of these qualities, if these methods are used hastily by the project managers, then they may lead to the production of low-quality software. Agile software development is receiving the attention of software developers and researchers thanks to its fast software delivery and flexible development plan capabilities (Sharma and Bawa, 2020).

During this worldwide crisis, only a few software companies have managed to deploy collaboration IT platforms/ interfaces, cloud-enabled IT infrastructure, and stringent security policies and guidelines to facilitate their product development teams to avail their e-resources (licensed software, tools/ components, e-manuals etc) from a centralized repository to continue working on various software processes related to their software projects. Some of them had even attempted to create an interface to mimic a virtual computer system through cloud services to their remote workers. This should be helpful to those who work with a simple computer system, and have sufficient internet bandwidth. But many IT companies that didn't have prior plan or such minimum arrangements experienced an overnight shift to remote work and product development. As carrying out software projects using 
employees from remote places is now becoming inevitable, IT companies should first understand the challenges associated with the existing software process models in practice and may opt for an alternate model to suit the product development using remote workers.

\section{THE CHALLENGES AHEAD}

Software development projects that are most likely to be affected to a greater extent during the crisis are projects that requiring work on updating a previously implemented software system within a short span of time and those that were promised by the IT vendors to be completed within a short turnaround time. Larger projects are relatively less affected, as their project duration may span from 1 year to 3 years. The existing models are meant to develop products based on well-elicited and welldefined requirements from the customer (Hatton et al., 2017). Moreover, these requirements need to be implemented by experienced developers on-site. Typically, these developers are provided with sufficient IT resources as well as sufficient time. Therefore, the developers and the project managers carrying out such projects will be sufficiently comfortable to complete a given task on time.

In contrast, during the worldwide crisis, IT companies are now required to embrace their customers' requisitions for immediate updation of their software products to incorporate a couple of critical operational requirements in no time. For example, a bank may opt to put on hold the automatic deduction of equated monthly instalments for a set of customers against their loans for a specified period. The incorporation of such operational requirements in a software product in use requires the implementation of a series of processes and sub-processes, and hence, such an implementation is the biggest challenge on hand, while testing it exhaustively in no time is the other adjoining herculean task. Achieving the above is possible only when the entire development team has an in-depth understanding of both the technology on which the product is being built and the complete project documentation. Such an understanding will facilitate the team in chalking out the sequence of tasks and processes to be executed to implement the requested requirements from the customer. Thus, in such a scenario, the project managers will be found working on either new software development or maintenance projects that will be tied over with tight deadlines, limited scope for feedback from customers, restricted IT resources and manpower, and a short span of time to understand the background of the project.

The project managers involved in such software projects still know little about what the development team members need to do on a day-to-day basis and how to monitor them and address their concerns. Any ad-hoc operations or processes that focus only on the completion and the rapid delivery of products will trigger the malfunctioning of the software product, thereby posing business and technical risks to the project at a later stage (Jbara et al., 2020). Hence, during any such worldwide crisis, the IT industry is expected to be guided by a model different from the usually practiced process model to quickly learn to list out the tasks for their on-going software development projects and for responding to their previously completed projects with respect to some swift updation and release for use by customers, in no time. What the current situation exposes is that the technical risks associated with the on-going new projects as well as the maintenance software projects have been unpriced and largely ignored. For many IT companies, the outright cancellation of projects, demand from the customer to deliver the product in reduced time than actual, and the same team of developers being engaged for multiple projects at a time are leading to chaos, thereby leaving no scope for follow-ups.

This should be a wake-up call for IT industries to proactively understand their project's vulnerabilities and define a number of potential actions to be taken during such crisis as guided by a software development model designed exclusively to help managers handle projects surpassing the challenges that may arise due to the crisis. In view of the need for such a model by IT industries, as an initiative by the SE community, we propose to present an abstract of an ISDM that could be of value to the project managers engaged in software projects during such a worldwide crisis. 


\section{RESEARCH DESIGN}

The need of the hour is to design an abstract of a new ISDM and figure out the elements that it should constitute. Such a model should be able to address the SE challenges that may be experienced by project managers while developing a new software product or working on software product maintenance during a worldwide crisis such as the COVID-19 crisis. To design an ISDM, we carried out brief study with IT professionals during March-April 2020, explained next. For this study, we adopted qualitative 'focused semi-structured' interview techniques suggested by King and Horrock (2010). The process of data collection involved formal and informal interview and discussions with project managers engaged in remote work through video conferencing sessions, and phone calls followed by responses to the questionnaire we sent them.

A total of 49 project managers from 22 IT services companies in India, the USA, and the UK, who are currently involved in an on-going or maintenance software project in their company participated in this study. These companies maintain CMM Level 5 quality standards and have been actively involved in providing IT solutions and consulting to their customers for the past two decades. In line with the previous research on empirical studies on IT projects (Klotins et al., 2019; King and Horrock, 2010; Lauesen, 2001), we then initiated the process of data collection from 49 project managers through a questionnaire to understand the key focus areas in our existing software development model and the specific areas where the focus should have been during the situations like the present crisis due to COVID-19 for effective software development and deployment. These managers had 11 to 17 years of IT experience from leading IT services companies' familiar with varied technologies and platforms, such as cloud, web applications, mobile applications, IoT and open-source software.

As the first step, we interacted 7 of the survey participants with extensive IT experience through video conferencing to better understand their present working model and culture. We also gained information about their currently adopted software development models and practices for their projects. We utilised this virtual interface to identify the SE terms that we should use in our survey to extract the key driving elements in the existing software development model and the desired elements according to the survey participants in the proposed model. The expected outcome of the survey was the identification of the most critical driving elements that should form the focal point of the proposed ISDM.

During the interaction, the project managers suggested the following SE terms (Leonardi, 2020; Pressman, 2010) that would better reflect their presently used SE models and practices in the survey. These terms included efficiency, verification, validation, control standards, flexibility, quality measures, reliability, integrity, prototype, and feedback.

Table 1 shows the description of these SE terms. Thus, in our survey instrument, we used all of these $10 \mathrm{SE}$ terms. The questionnaire was pilot tested with randomly selected 9 survey participants among 49 project managers chosen for this study to examine the wording, applicability, readability and understandability of the questions. The questionnaire was then shared with all the survey participants comprising of 49 project managers by email. The responses to the questionnaire were expressed by these managers as Likert-scale ratings (Rajendran et al., 2006) by choosing a number between 1 ('strongly disagree') and 5 ('strongly agree'), particularly to understand the key focus areas in our existing software development model and the specific areas where the focus should have been during the situations like the present crisis due to COVID-19 for effective software development and deployment.

Using the survey, we requested the project managers to help us identify the key driving elements in the existing software development models as well as the elements that they would strongly prefer in the ISDM. This will help us change the focal point of the existing model in the new one on the basis of the recommendations by the project managers. The respondents subjectively evaluated each SE term on a Likert scale of 1 to 5, as discussed above. 
Table 1. Description of SE terms (Pressman, 2010)

\begin{tabular}{|l|l|}
\hline \multicolumn{1}{|c|}{ SE term } & \multicolumn{1}{c|}{ Description } \\
\hline Efficiency & Faster response time by the software despite shortage of resources \\
\hline Verification & $\begin{array}{l}\text { Evaluating software products during software development to ascertain whether they } \\
\text { meet the specified requirements }\end{array}$ \\
\hline Validation & $\begin{array}{l}\text { Evaluating software products at the end of the software development to determine } \\
\text { whether the software meets the customer's expectations and requirements }\end{array}$ \\
\hline Control standards & Adherence to audit, regulatory bodies, and statutory bodies \\
\hline Flexibility & Ability of the software to quickly adapt to the changes in business \\
\hline Quality measures & Adherence to quality models such as ISO and CMM \\
\hline Reliability & Ability of the software to function for the stated constraints without any error \\
\hline Integrity & How secure is the software against threats \\
\hline Prototype & Incomplete versions of the software program being developed \\
\hline Feedback & $\begin{array}{l}\text { Feedback from customers helps project managers get a better understanding of the } \\
\text { customers' requirements }\end{array}$ \\
\hline
\end{tabular}

\section{EMPIRICAL BODY OF EVIDENCE}

As part of this study, the responses obtained from the 49 project managers of IT companies through an email based survey and our observations on it are discussed next. Figure 1 shows the responses from 49 project managers that showcase the top driving elements of the existing software development models and the proposed ISDM. This will help the practitioners to better understand the evolution of the proposed ISDM from the existing SE paradigm.

\section{DESIGNING AN INTERACTIVE SOFTWARE DEVELOPMENT MODEL (ISDM)}

From Figure 1, one could easily infer the key aspects (focal points) of the existing software development models and the ISDM, as observed by our survey respondents. The numbers shown against each key aspect in the Figure 1 shows the summation of scores provided by 49 project managers who participated in our study. The scores were provided by them for each of these key aspects using a Likert scale ranging from 1 to 5 .

For the existing models in practice (Sutton, 2000; Melegati et al., 2019), the participants concurred that quality measures and feedback-based design and development are the key focal points. However, on the basis of their recently gained project management experience, they expressed the desire that the proposed or any new model for software projects executed during a crisis or disaster period have the control standards and the verification and validation mechanism in an iterative manner as the key focal points rather than depending on the customers for their feedback for every intermediate deliverable.

The IT services companies those who are running their operations with limited human resources and restricted IT infrastructures cannot be expected to adopt any established (rigorous traditional) software development methods beyond lean development principles (Poppendieck \& Poppendieck, 2003; Blank, 2013) or agile methods (Paternoster et al., 2014; Iniyat et al., 2015; VenuGopal et al., 2017) for requirements engineering process and product development. By the term 'traditional', we refer to software development methods and models such as waterfall, prototype, iterative, spiral and rapid application development being used in IT services companies during software development commencing from the requirements engineering process through software testing (Pressman, 2010). Agile methods are designed for embracing changes dynamically during product development and 


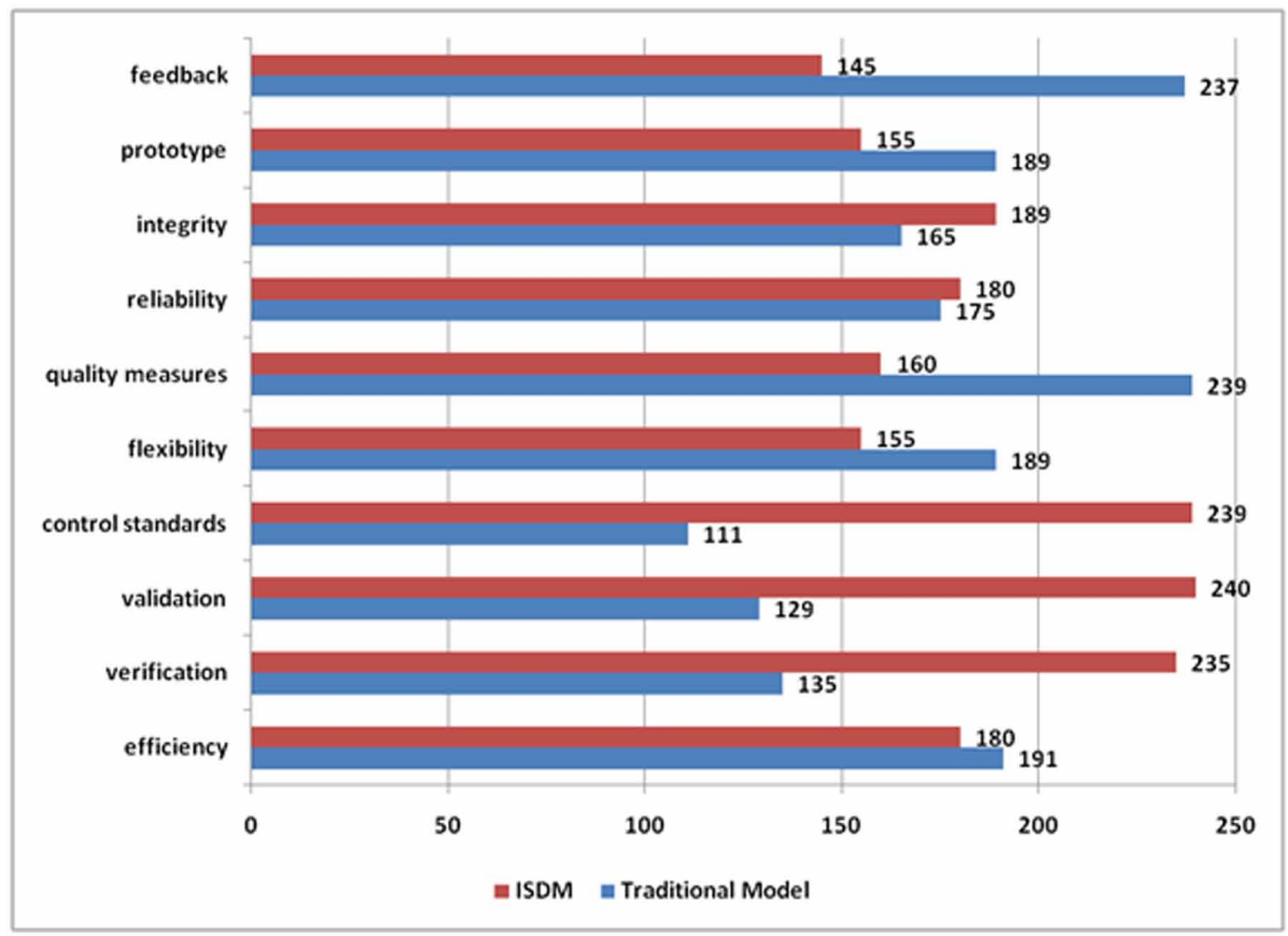

dealing with uncertainties, however, a few of the IT services companies those who are applying them partially for their software development find it hard to implement the agile practices systematically, owing it to shortage of IT resources and time constraints (Klotins et al., 2019). Unlike the requirements engineering processes in large and well established IT services companies, where requirements are well defined and classified as functional and non-functional (e.g. user interface and information security), in IT services companies with limited resources, requirements are drawn out of the customer's experiences on their usage or familiarity with the software product to be built and the market value it is expected to bring to the customer's organization.

Any rapid development of a software product or its updation should never ignore control standards which refer to the prescribed guidelines or standards outlined by the respective regulatory bodies (Sharma and Bawa, 2020). For example, any operational requirements implemented by a banking IT application should strictly adhere to the corresponding regulatory bodies, such as the reserve bank or the ministry of finance. Thus, we found that the project managers who participated in our survey strongly suggested that the control standards and the verification and validation mechanism be the key focus of any new model for software projects that face threats and challenges from various quarters because of a crisis.

Figure 2 shows a high-level view of the ISDM. The most desired focal points of the model are the attributes of the process and the product. 


\begin{tabular}{|l|l|l|}
\hline & \multicolumn{2}{|c|}{ Key Aspects } \\
\hline & $\begin{array}{l}\text { Traditional Model } \\
\text { (Typically Incorporates) }\end{array}$ & $\begin{array}{l}\text { ISDM } \\
\text { (Should Work Toward) }\end{array}$ \\
\hline Process & Quality measures & Control Standards \\
\hline Attributes & Learning through & $\begin{array}{l}\text { Learning through iterative } \\
\text { Verification and }\end{array}$ \\
\hline Attributes & Feedback & \begin{tabular}{l} 
Validation \\
\hline
\end{tabular} \\
\hline
\end{tabular}

\section{LOOKING AHEAD}

Project managers cannot be expected to apply rigorous SE methodologies or follow such models in their software projects when they run short of the usually provided IT resources and manpower and that too when they were asked to work from remote locations (Unterkalmsteiner et al., 2012). Doing so will not be effective irrespective of the amount of time spent on adhering to such practices. Project managers who participated in our present study indicated the necessity to identify the practices required to develop a software product during a crisis period such as the present one faced by IT industries globally because of COVID-19. We have made this preliminary effort to highlight the key focal areas required for a structured software development model to be used by the project managers during any crisis or disaster. The high-level view of the ISDM presented here will definitely provide a roadmap for the SE researchers to deepen their research on the suggested focal points in the immediate future in order to develop a more structured and tested model forthe IT industry.

The SE community is expected to bear in mind the diversity of context and the view points of project managers in the adoption of SE processes and practices when they are experiencing high uncertainty and restricted resources because of a crisis due to a natural disaster or the COVID-19 pandemic. From this study, one can easily infer that the criteria preferred by the project managers to monitor and assess software development projects vary in importance during normal and crisis times, as they transform the complex processes and larger workflows in their software projects into smaller activities and tasks that canbe executed independently at diverse locations through self-manageable team members. Moreover, with fewer interfaces among the team members as well as the customers for instant feedback and suggestions, this seems to be the only viable option for project managers during crisis periods.

We believe that our framework (ISDM) would enable both matured startups as well as other leading IT services companies to increase the success rate of their projects by helping them focus the process and product attributes from the perspective of quality. The IT services companies after assessing the projects for their quality measures and preferring a quadrant from the ISDM other than commensurate with their maturity level may consider evaluating the trade-offs among the benefits, costs, and risk. To explore the generalizability of our proposed framework, we admit the need for future case studies in the IT services companies of different sizes and maturity. Future research may also focus on other latest practices such as usage of DevOps during deployment as well.

Due to COVID-19, there also has been a massive layoff of IT employees across the globe and a huge reduction in gross monthly pay across IT industries all over the world. The quantum of information 
technology investment by several industries have also come down drastically, thereby forcing them to look for a quote with reduced project costs by IT services companies. This in turn will pressurize these companies to look for alternate ways and means for developing software products. In summation, the crisis due to COVID-19 is a story which involves high uncertainty coupled with a shortage of resources. However, what is evident is that the COVID-19 crisis has introduced new challenges to the IT industry, which call for a measured, practical, and informed approach from project managers to successfully complete their on-going projects on time. We firmly believe that preparing for shifts will help the IT industry navigate in the post COVID-19 world with minimal effort.

\section{NOTE}

This research received no specific grant from any funding agency in the public, commercial, or notfor-profit sectors. 


\section{REFERENCES}

Allen, E., \& Christopher, S. (2007). Likert Scales and Data Analyses. Quality Progress, 64-65.

Balijepally, V. G., DeHondt, G., Sugumaran, V., \& Nerur, S. (2017). Agility in Software Development and Project Value: An Empirical Investigation. Journal of Database Management, 28(4), 40-59. doi:10.4018/ JDM.2017100103

Chen, J., \& Huang, S. J. (2009). An empirical analysis of the impact of software development problem factors on software maintainability. Journal of Systems and Software, 82(6), 981-992. doi:10.1016/j.jss.2008.12.036

Gralha, C., Damian, D., Wasserman, A., Goulao, M., \& Araujo, J. (2018). The evolution of requirements practices in software startups. Proceedings of the 40th International Conference on Software Engineering (ICSE '18), 823-833. doi:10.1145/3180155.3180158

Hatton, L., \& Rutkowski, A. F. (2019). Lessons must be learned'-But are they? IEEE Software, 36(4), 91-95. doi:10.1109/MS.2019.2909330

Hatton, L., Spinellis, D., \& Van Genuchten, M. (2017). The long-term growth rate of evolving software: Empirical results and implications. Journal of Software Evolution Process, 29(5), 1-10. doi:10.1002/smr.1847

Iniyat, I., Salim, S. S., Marczak, S., Daneva, M., \& Shamshirband, S. (2015). A systematic literature review on agile requirements engineering practices and challenges. Computers in Human Behavior, 51, 915-929. doi:10.1016/j.chb.2014.10.046

Jbara, A., Bibliowicz, A., Wengrowicz, N., Levi, N., \& Dori, D. (2020). Toward integrating systems engineering with software engineering through Object-Process Programming. International Journal of Information Technology, 1(1), 1-35.

Karlsson, L., Dahlstedt, A. G., Natt Och Dag, J., Regnell, B., \& Persson, A. (2007). Requirements engineering challenges in market-driven software development - An interview study with practitioners. Information and Software Technology Journal, 49(63), 588-604. doi:10.1016/j.infsof.2007.02.008

King, N., \& Horrock, C. (2010). Interviews in Qualitative Research. Sage (Atlanta, Ga.).

Klotins, E., Unterkalmsteiner, M., \& Gorschek, T. (2019). Software engineering in start-up companies: An analysis of 88 experience reports. Empirical Software Engineering, 24(1), 68-102. doi:10.1007/s10664-018-9620-y

Lauesen, S. (2001). Software Requirements: Styles and Techniques. Wiley.

Leonardi, P. (2020). You're Going Digital— Now What? Sloan Management Review, 61(2), 1-10.

Melegati, J., Goldman, A., Kon, F., \& Wang, X. (2019). A model of requirements engineering in software startups. Information and Software Technology, 109(1), 92-107. doi:10.1016/j.infsof.2019.02.001

Paternoster, N., Giardino, C., Unterkalmsteiner, M., Gorschek, T., \& Abrahamsson, P. (2014). Software development in startup companies: A systematic mapping study. Information and Software Technology, 56(10), 1200-1218. doi:10.1016/j.infsof.2014.04.014

Poppendieck, M., \& Poppendieck, T. (2003). Lean Software Development: An Agile Toolkit. Addison-Wesley Professional.

Pressman, S. R. (2010). Software Engineering - A Practitioner's Approach (International Edition). McGraw-Hill.

Rajendran, C., Issac, G., \& Anantharaman, R. N. (2006). An instrument for the measurement of customer perceptions of quality management in the software industry: An empirical study in India. Software Quality Journal, 14(4), 291-308. doi:10.1007/s11219-006-0037-2

Sharma, A., \& Bawa, R. K. (2020). Identification and integration of security activities for secure agile development. International Journal of Information Technology, 1-14.

Sutton, S. M. (2000). The Role of Process in Software Start-ups. IEEE Software, 17(4), 33-39. doi:10.1109/52.854066 
Unterkalmsteiner, M., Gorschek, T., Islam, A., Cheng, C. K., Permadi, R., \& Feldt, R. (2012). Evaluation and measurement of software process improvement: A systematic literature review. IEEE Transactions on Software Engineering, 38(2), 398-424. doi:10.1109/TSE.2011.26

Wieringa, R. J., \& Daneva, M. (2015). Six strategies for generalizing software engineering theories. Science of Computer Programming, 101(1), 136-152. doi:10.1016/j.scico.2014.11.013

Zykov, S. V. (2016). Software Methodologies: Are Our Processes Crisis-Agile? In Crisis Management for Software Development and Knowledge Transfer. Smart Innovation, Systems and Technologies, 61. Springer. doi:10.1007/978-3-319-42966-3_3

Sudhaman Parthasarathy, PhD, is a Professor in the Department of Computer Applications, Thiagarajar College of Engineering, Madurai, India. A habitual rank holder, he has been teaching at the post-graduate level for the past 19 years. He has published research papers in peer reviewed conferences and International Journals such as Computers in Industry, Software Quality Journal, Journal of Systems and Software, International Journal of Project Management, Computer Standards and Interfaces and Business Process Management Journal. He has authored several chapters in the refereed edited books of IGI, USA and Springer, London. He is the Editor-in-Chief for the Edited Book "Enterprise Information Systems and Implementing IT Infrastructures: Challenges and Issues" which was published in May 2010. He is also in the review board of reputed international journals in MIS, ERP and software systems from Wiley, Elsevier, Springer and Emerald. His current research interests include enterprise information systems, ERP software engineering using design science.

Thangavel Chandrakumar, PhD, is an Assistant Professor in Data Science in the Department of Computer Applications at Thiagarajar College of Engineering, Madurai, India. He has completed his PhD in Anna University, Chennai in January 2016. He holds a Master's Degree in Computer Applications from Madurai Kamaraj University, Madurai. His research interests include software engineering, Enterprise Resource Planning (ERP), and software quality. He has published research papers in refereed conferences and top-ranking journals such as Computer Standards \& Interfaces, International Journal of Project Management and International Journal of Enterprise Information System. He has authored several Book chapters in the refereed edited book of Springer. 